\title{
PEMANFAATAN BAMBU OLEH MASYARAKAT PENGRAJIN DESA MENYABO KECAMATAN TAYAN HULU KABUPATEN SANGGAU
}

\author{
(Utilization of bamboo by the village craftsmen in the sub-district of Tayan Hulu of Sanggau \\ Regency)
}

\author{
Meysa Florensiani Sinaga, Iskandar AM, Eddy Thamrin \\ Fakultas Kehutanan Universitas Tanjungpura Jl. Daya Nasional, Pontianak 78124 \\ Email: meysasinaga14@yahoo.co.id
}

\begin{abstract}
Bamboo is a very useful plant for people's lives. Traditionality bamboo is commonly used for various purposes such as household utensils, handicrafts and construction materials for building houses and foodstuffs. The purpose of this study is to determine the types of bamboo and parts of the bamboo plant that are used, to find out in what form the benefits of the bamboo plant, to describe the types of product made from the bamboo plant that are used by the people of Menyabo Village of Tayan Hulu Subdistrict of Sanggau Regency. The method used in this study is a direct survey method in the field; data collection techniques were carried out through interviews using interview guidelines, and data were obtained using a descriptive method. The results of this study found 2 species of bamboo: Schizostacyum zollingeri Stuedel (reed bambbo) and gigantochloa balui K M Wong (abe bamboo). they use bamboo by craftsmen such as nyiruk, ketoro, atom, baskets, rice containers and jarai, home building construction materials and vegetable food ingredients (bamboo shoots).
\end{abstract}

keywords: Bamboo, Craftsman, Utilization

\section{PENDAHULUAN}

Wilayah Desa Menyabo merupakan bagian dari Kecamatan Tayan Hulu Kabupaten Sanggau, Luas Kecamatan ini 7.177 ha. Potensi tanaman bambu cukup dominan tumbuh disetiap kawasan hutan. Jumlah penduduk Desa Menyabo 710 KK, suku masyarakat Desa Menyabo mayoritas bersuku Dayak Taba (Be'Aje). Agama yang dianut mayoritas agama Kristen Protestan. Masyarakat Desa Menyabo juga memiliki sistem kekerabatan seperti masyarakat Dayak pada umumnya memiliki kekerabatan bilateral. Pembentukan kelompok kerja, masyarakat Desa Menyabo pada umumnya memiliki pekerjaan pokok dan sampingan (berladang dan kerja kebun).Dan terkadang bagi kaum lakilaki dan perempuan yang pandai membuat anyaman mereka dapat melakukan pekerjaan menganyam untuk keperluan sendiri.

Di dalam hutan terdapat tumbuhan hasil hutan bukan kayu (HHBK) mencakup berbagai jenis sumber daya hutan, yang dimanfaatkan untuk berbagai kepentingan rumah tangga maupun perdagangan. Manfaat hasil hutan bukan kayu diantaranya sebagai sumber makanan, rempah-rempah, resin, obat-obatan, pengawet makanan, dan berbagai bentuk kerajinan sebagai penunjang kehidupan masyarakat. Manfaat hasil hutan bukan kayu yang 
banyak dimanfaatkan seperti jenis bambu (Beer 2005).

Hutan merupakan sumber daya alam yang memberikan manfaat besar bagi manusia baik secara ekologis, ekonomis maupun sosial baik itu hasil hutam berupa kayu maupun hasil hutan bukan kayu salah satunya adalah bambu termasuk tumbuhan yang mempunyai banyak manfaat dalam kehidupan sehari-hari. Dengan adanya kehadiran bambu tersebutmaka akan muncul salah satu siakp kebudayaan dalam memanfaatkan bambu. Bambu dapat di manfaatkan sebagai bahan bangunan rumah, bahan kerajinan tangan (produk turunan) dan bahan makanan sayuran (rebung).

Masyarakat Desa Menyabo memenuhi kebutuhan hidup mereka bagaimana berfikir dan mengelola amal lingkungannya dengan adanya jenisjenis bambu tersebut muncul salah satu ide yang diwarisi para nenek moyang mereka secara turun temurun hingga saat ini dapat mereka kembangkan menjadi pola kebiasaan yang dilakukan dalam hidup mereka sehari-hari. Masyarakat pengrajin Desa Menyabo memanfaatkan bambu sebagai bahan kerajinan tangan seperti produk turunan berupa anyaman secara tidak langsung berupa nyiruk, ketoro, atom, jarai, keranjang dan bakul. Serta bambu tersebut dapat dimanfaatkan sebagai bahan konstruksi banguanan rumah, secara langsung dapat dimanfaatkan seperti ritual pesta penyambutan padi baru (naik dango) dan natalan sebagai tempat atau alat masak seperti lemang.
Masyarakat juga memanfaatkan rebungnya sebagai sumber bahan pangan.

Bambu merupakan bagian besar dari rumput-rumputan namun bambu memiliki peran penting bagi Bangsa Indonesia khususnya (Kalimantan Barat) untuk memenuhi kebutuhan hidup sehari-hari. Pemanfaatan bambu oleh masyarakat Desa Menyabo dapat dilihat beberapa rumusan masalah yaitu jenis tumbuhan bambu, bagian tumbuhan bambu yang dimanfaatkan oleh masyarakat pengrajin, jenis-jenis tanaman bambu yang dimanfaatkan oleh masyarakat pengrajin di Desa Menyabo, dan jenis-jenis anyaman yang dihasilkan dari tumbuhan bambu yang dimanfaatkan oleh masyarakat pengrajin Desa Menyabo Kecamatan Tayan Hulu Kabupaten Sanggau. Menurut hasil penelitian Iqbal dkk (2014) bambu dikenal sebagai hasil hutan bukan kayu yang pemanfaatannya sudah berlangsung lama dan sudah di gunakan turun temurun oleh masyarakat Desa Menyabo.

Harga bambu juga relatif murah dibanding bahan bangunan lain karena banyak ditemukan di sekitar pemukiman pedesaan bahkan juga di perkotaan. Tanaman bambu di Indonesia ditemukan mulai dari dataran rendah sampai pegunungan. Pada umumnya bambu ditemukan di tempattempat terbuka dan daerahnya bebas dari genangan air.

Penelitian ini bertujuan untuk mengetahui jenis bambu, bagian 
tumbuhan bambu yang dimanfaatkan, mengetahui bentuk-bentuk pemanfaatan bambu dan mendeskripsikan jenis anyaman yang dihasilkan dari tumbuhan bambu yang dimanfaatkan masyarakat pengrajin Desa Menyabo. Manfaat dari penelitian tentang pemanfaatan bambu oleh masyarakat Desa Menyabo Kecamatan Tayan Hulu Kabupaten Sanggau meliputi: Sebagai sumber informasi khususnya bagi masyarakat pengrajin di Desa Menyabo tentang jenis dan bagian tumbuhan bambu yang dimanfaatkan, memberikan gambaran mengenai pemanfaatan bambu secara utuh dan menjembatani pengetahuan tentang bentuk pemanfaatan tumbuhan bambu dan jenis anyaman yang dihasilkan dari pemanfaatan tumbuhan bambu secara tradisional yang dilakukan sejak turun temurun dan akan menjadi data dasar pengembangan pengetahuan dalam memanfaatkan bambu yang berkelanjutan.

\section{METODE PENELITIAN}

Jenis penelitian ini merupakan penelitian deskriptif, dengan metode survey. Teknik pengumpulan data menggunakan alat bantu yaitu pedoman wawancara berupa bentuk- bentuk pertanyaan yang diarahkan kepada sejumlah responden. Pengambilan sampel dilakukan menggunakan sensus atau sampling penuh yaitu semua masyarakat pengrajin dijadikan sebagai responden sebanyak 25 pengrajin bambu. Melihat dan mendokumentasikan bagaimana cara atau sistem dari jenis-jenis pemanfaatan bambu yang diamanfaatkan oleh masyarakat Desa Menyabo sekaligus mengtahui jenis- jenis bambu juga dilakukan dengan mengamati bentuk batang, warna batang, daun, tipe pertumbuhan dan pengenalan nama lokal dan nama daerah serta manfaat masing-masing setiap jenis bambu. Alat yang digunakan dalam penelitian ini antara lain: pedoman wawancara, alat tulis, perekam suara, buku identifikasi tumbuhan, peta lokasi dan kamera. Pengambilan data penelitian ini mulai tanggal 28 juni sampai dengan 28 juli 2019.

\section{HASIL DAN PEMBAHASAN}

Karakteristik responden dalam penelitian ini adalah masyarakat pengrajin yang memanfaatkan bambu di Desa Menyabo Kecamatan Tayan Hulu Kabupaten Sanggau. Jumlah responden yang diambil adalah sebanyak $25 \mathrm{KK}$ dari $710 \mathrm{KK}$. Responden dipilih seacara Purposive sampling yaitu (bersifat tidak acak/sengaja dipilih) dengan melihat persyaratan sebagai berikut:

1. Masyarakat yang berdomisili 10 tahun di Desa Menyabo

2. Mempunyai pekerjaan sampingan sebagai pengrajin anyaman bambu

3. Mempunyai keterampilan dalam membuat kerajinan anyaman bambu

Penetapan 25 sampel sudah cukup untuk mewakili seluruh masyarakat pengrajin Desa Menyabo yang memanfaatkan bambu. Berikut adalah pengolongan karakteristik responden berdasarkan, umur, jenis kelamin, pendidikan, pekerjaan, suku, status perkawinan. Penduduk Desa Menyabo 
yang menjadi responden dalam penelitian ini terdiri dari laki-laki 1 orang dan perempuan 24 orang. Desa Menyabo ini penduduknya banyak didominasi oleh suku Dayak, dan sisanya masing-masing adalah bersuku jawa, batak.
Responden berdasarkan tingkat umur terhadap 25 responden, responden berumur 20-40 tahun berjumlah 3 responden, 7 responden pada tingkat umur 41-60 tahun, responden pada tingkat umur 61-80 tahun sejumlah 15. Jumlah Responden Pengrajin berdasarkan tingkat umur.

Tabel 1. Jumlah Responden Pengrajin Berdasarkan Tingkat Umur (number of respondent craftsmen by age level)

\begin{tabular}{lcc}
\hline No & Tingkat Umur & Jumlah (KK) \\
\hline 1 & $20-40$ & 3 \\
2 & $41-60$ & 7 \\
3 & $61-80$ & 15 \\
\hline & Jumlah & $\mathbf{2 5}$ \\
\hline
\end{tabular}

Sumber : Hasil Analisis Data Primer 2019

Berdasarkan tingkat pendidikan terhadap 25 responden masyarakat pengrajin Desa Menyabo, terdapat 22 responden pengrajin tidak tamat sekolah, 2 responden pengrajin tamat sekolah dasar (SD), 1 responden

Tabel 2. Karakteristik Responden Berdasarkan Tingkat pendidikan (characteristic of respondent by eduqation level)

\begin{tabular}{lcc}
\hline No & Tingkat pendidikan & Jumlah (KK) \\
\hline 1 & Tidak sekolah & 22 \\
2 & Sekolah Dasar (SD) & 2 \\
3 & Sekolah menegah atas (SMA) & 1 \\
\hline & Jumlah & $\mathbf{2 5}$ \\
\hline
\end{tabular}

Sumber : Hasil Analisis Data Primer 2019

Tingkat pekerjaan responden pengrajin berdasarkan pekerjaan pokok dan pekerjaan sampingan, jumlah responden pengrajin pada tingkat (petani cabai dan menganyam) terdapat 8 responden, (petani penoreh getah dan menganyam) terdapat 13 responden, pengrajin tamat sekolah menengah atas (SMA). Untuk lebih jelasnya bisa dilihat pada table 2. Karakteristik responden berdasarkan tingkat pendidikan. (petani ladang, beternak dan menganyam) terdapat 3 responden (petani padi dan menganyam) terdapat 1 responden, untuk lebih jelasnya dapat dilihat pada table 3 . Responden pada tingkat pekerjaan pokok dan sampingan. 
Tabel 3. Responden Pada Tingkat Pekerjaan Pokok dan Sampingan (respondent in main work and side work level)

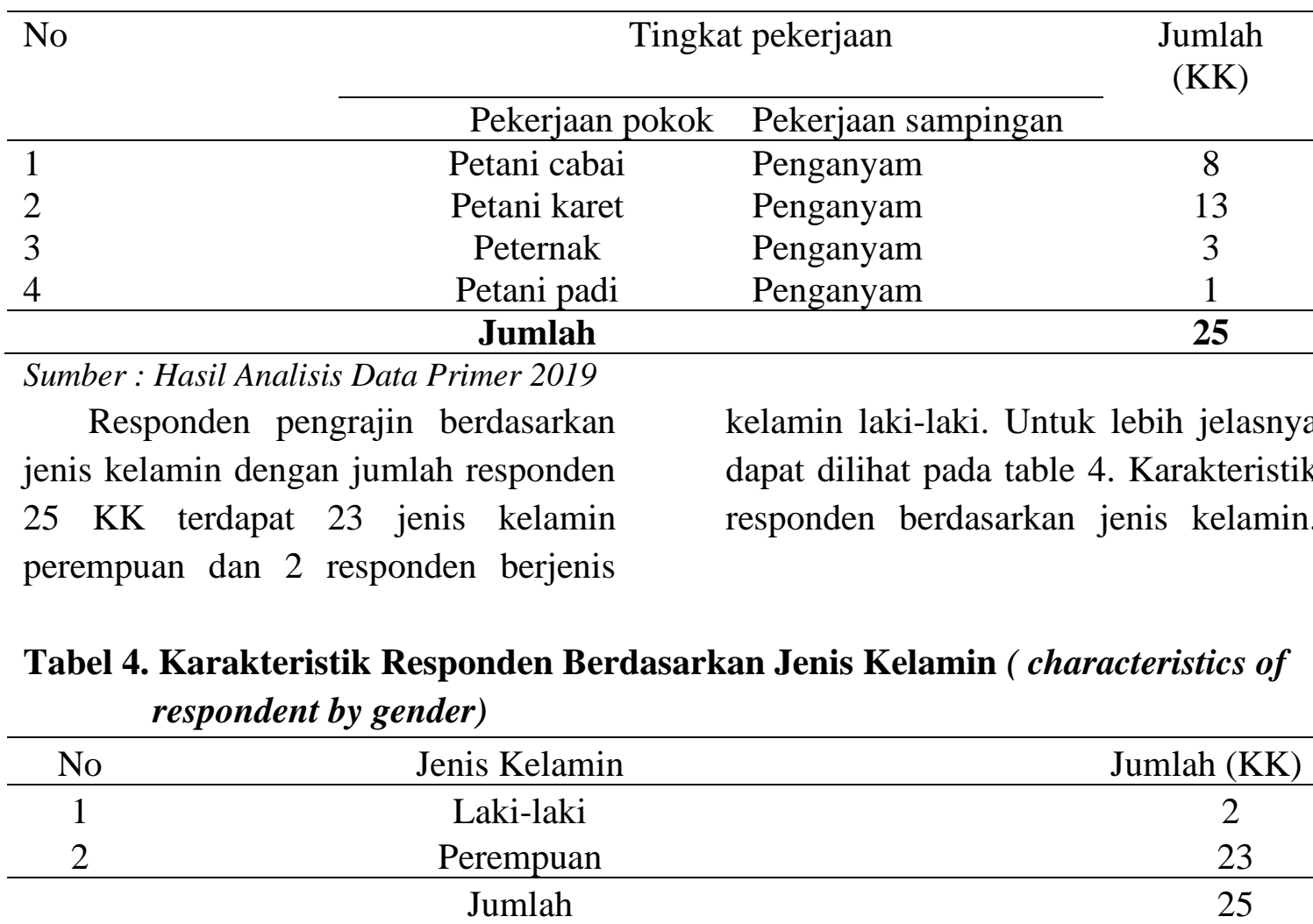

Sumber :Hasil Analisis Data Primer 2019

Berdasarkan hasil penelitian diperoleh dua jenis bambu yang dimanfaatkan oleh masyarakat pengrajin di Desa Menyabo yang berasal dari 2 genus yaitu
Schizotachyum dan Gigantochloa. Pemanfaatan lebih banyak pada anyaman dan konsumsi dan bagian yang banyak digunakan adalah batang dan tunas seperti tersaji pada Tabel 5.

Tabel 5. Jenis -jenis Bambu yang Dimanfaatkan Oleh Masyarakat Desa Menyabo ( kinds of bamboo used by villages in Menyabo )

\begin{tabular}{llllc}
\hline No & $\begin{array}{l}\text { Jenis } \\
\text { bambu }\end{array}$ & Genus & Nama latin & Nama lokal \\
\hline 1 & $\begin{array}{l}\text { Bambu } \\
\text { buluh }\end{array}$ & Schizostacyum & $\begin{array}{l}\text { Schizostacyum } \\
\text { zollingeri stuedel }\end{array}$ & Buro'k \\
2 & $\begin{array}{l}\text { Bambu } \\
\text { abe }\end{array}$ & Gigantochloa & $\begin{array}{l}\text { Gigantochloa } \\
\text { balui K.M Wong }\end{array}$ & Tarek'ng \\
\hline
\end{tabular}

Sumber : Hasil analisis data primer 2019. 
Bagian tumbuhan bambu yang dimanfaatkan masyarakat dari bambu buluh yaitu bagian batangnya dan bambu abe masyarakat memanfaatkan batang dan tunas. Menurut penelitian Andoko (2003) bahwa bagian bambu yang dimanfaatkan masyarakat di Kecamatan Tayan Hulu Kabupaten Sanggau yaitu batang dan tunas muda bambu (Gambar 1). Alasan masyarakat mengkonsumsi tunas mudanya sebagai sayuran karena dapat dimakan.
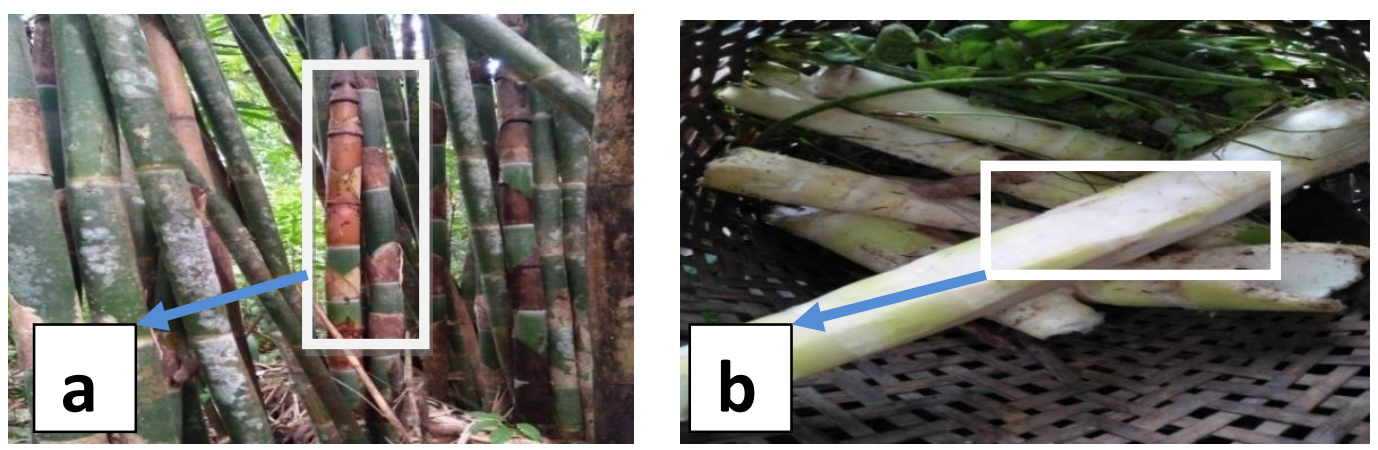

Gambar 1. Bagian tumbuhan bambu yang dimanfaatkan oleh masyarakat Keterangan: a. Batang bambu

b. Tunas muda bambu

Tumbuhan bambu dimanfaatkan masyarakat dalam berbagai bentuk untuk mendukung kegiatan keseharian masyarakat pengrajin. Pemanfaatan tumbuhan bambu oleh masyarakat terbagi atas bentuk anyaman, pembungkus makanan, sayuran dan konstruksi bahan bangunan masyarakat. Bentuk pemanfaatan tumbuhan bambu oleh masyarakat pengrajin Desa Menyabo yang berasal dari bagian tumbuhan bambu yaitu batang dan tunas, batang tumbuhan dimanfaatkan masyarakat sebagai anyaman, pembungkus makanan dan konstruksi bangunan rumah. Tunas tumbuhan bambu dimanfaatkan masyarakat sebagai makanan atau sebagai sayuran masyarakat. Menurut hasil penelitian Andoko (2003) bentuk pemanfaatan bambu oleh masyarakat di Desa Menyabo Kecamatan Tayan Hulu Kabupaten Sanggau berupa anyaman, pembungkus makanan, makanan/sayuran dan kosntruksi bahan bangunan rumah.

Di Desa Menyabo tunas bambu dimanfaatkan oleh masyarakat sebagai sayuran saja. Masyarakat kurang terampil dalam mengolah atau memanfaatkan jenis-jenis bambu, hal ini menyebabkan masyarakat tidak memanfaatkan jenis bambu ini untuk keperluan kesenian atau anyaman. Sedangkan menurut Widjaja (2001), bagi orang sunda sunda dan jawa rebungnya biasa digunkan untuk sayur dan batang digunkan untuk pilar kontruksi bangunan, mebel, industry sumpit, tusuk gigi, kertas dan digunakan untuk membuat alat musik bambu tradisional seperti bas.

Jenis anyaman yang dihasilkan dari pemanfaatan tumbuhan bambu oleh masyarakat di Desa Menyabo berupa Ketoro, Nyiruk, Jarai, Atom, keranjang, bakul, keranjang kecil, kandang ayam, 
makanan dan sayuran.
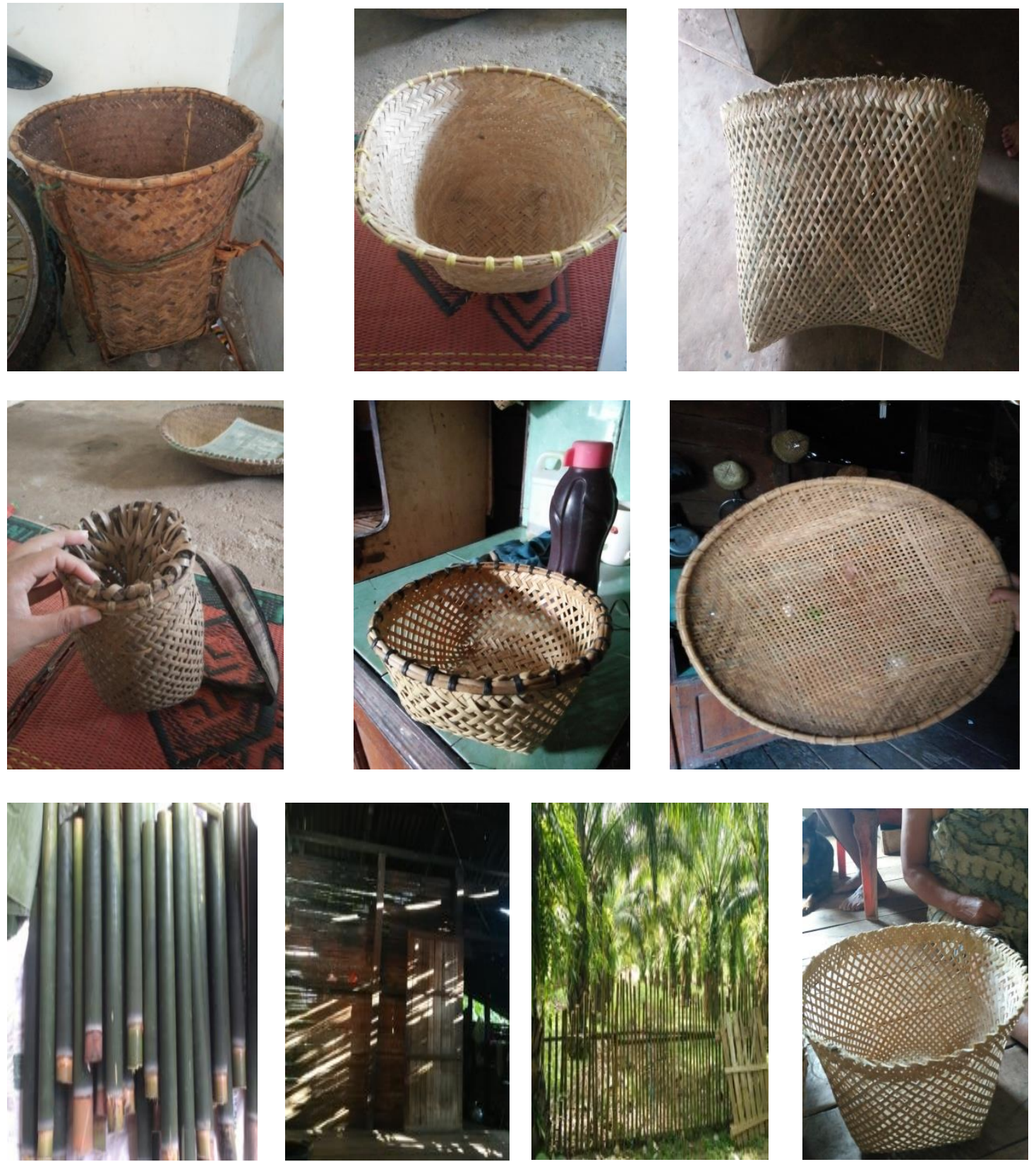

Gambar 3. Jenis-jenis anyaman yang dihasilkan oleh masyarakat pengrajin

Masyarakat memanfaatkan Bambu sebagai anyaman seperti nyiruk, atom, jarai, bakul, ketoro. Nyiruk merupakan alat penampi beras dan biji-biji lainnya seperti jagung dan kacang untuk menghilangkan kulit ari biji. Jarai merupakan alat pengangkut sawit. Atom merupakan alat pengangkut padi dari sawah. Bakul digunakan masyarakat sebagai penyimpan cabai dan ketoro dimanfaatkan sebagai penangkap ikan disungai.

Pemanfaatan tumbuhan bambu yang dilakukan oleh masyarakat Desa Menyabo secara tradisional, turutemurun dari nenek moyang dan 
interaksi masyarakat dengan alam sekitar sehingga terjadi pemanfaatan terhadap tumbuhan bambu dalam kegiatan keseharian. Menurut Soekarman dan Risman (1992); Siska et al. (2015) pada umumnya perwarisan pengetahuan tradisional dilakukan secara lisan dari generasi ke generasi.

Proses yang dilakukan masyarakat dalam pemanfaatan tumbuhan bambu melalui beberapa tahap yaitu pemanenan, pembersihan tahap pertama, pengeringan, pembersihan tahap kedua, pembuatan produk.

\section{Pemanenan}

Masyarakat yang mengambil tumbuhan bambu di hutan dengan memperhatikan bahwa tumbuhan bambu tersebut memiliki kulitas yang bagus, terutama tumbuhan bambu yang sudah pantas dipanen, batang tidak rusak. Pemanenan yang dilakukan masyarakat dengan cara memotong bagian pangkal tumbuhan bambu, kemudian memotong pucuk bambu tersebut sehingga memperoleh panjang batang yang diinginkan. Batang tumbuhan bambu yang sudah dipotong bagian pangkal dan ujung, kemudian masyarakat memotong lagi menjadi bagian-bagian yang panjangnya sesuai dengan keinginan.

Tumbuhan bambu yang dipanen masyarakat dengan memotong tumbuhan bambu yang masih muda, memotong bagian pangkal dan bagian pucuk bambu serta membersihkan bulubulu. Peralatan yang digunakan dalam pemanenan yaitu parang atau pisau.

2. Pembersihan tahap pertama
Setelah pemanenan masyarakat melakukan pembersihan tahap pertama, dengan mencuci batang tumbuhan bambu di air dan kemudian membelah batang tumbuhan bambu menjadi beberapa bagian yang disesuaikan dengan kebutuhan. Bagian batang tumbuhan bambu yang sudah dibelah, kemudian membersihkan dengan membuang serat tengah dari batang tumbuhan bambu tersebut atau di rawut yang menggunakan alat yaitu pisau kecil.

3. Pengeringan

Setelah dilakukan pembersihan tahap pertama, bagian-bagian batang tumbuhan bambu dilakukan pengeringan dengan menjemur di bawah sinar matahari dan di asapkan di atas tungku dapur masyarakat yang menggunakan kayu bakar. Alsan masyarakat melakukan pengeringan tersebut bertujuan mengurangi kadar air yang tersimpan di dalam batang tumbuhan bambu agar dalam pembuatan produk tidak terjadi penyusutan.

4. Pembersihan tahap kedua

Bambu yang sudah kering kemudian dibersihkan lagi atau dirawut kembali dengan menggunakan pisau kecil agar bagian tersebut menjadi alus, lembut dan rapi supaya dalam pembuatan produknya mudah dikerjakan.

5. Pembuatan produk

Bagian-bagian bambu yang sudah dibersihkan dilakukan proses penganyaman menjadi berbagai produk. Dalam proses penganyaman dilakukan suatu pengerapian yang menggunakan 
alat yaitu simal dan pemodat agar produk yang dihasilkan kelihatan indah dan bagus.

Pengetahuan masyarakat pengrajin Desa Menyabo dalam memanfaatkan jenisjenis bambu dan membuatnya menjadi produk turunan yang dapat memberikan nilai tambah tersebut umumnya mereka memiliki pengetahuan dari orang tua mereka. Pengetahuan secara turun temurun, pengetahuan lokal dapat disimpulkan dari masyarakat setempat selanjutnya dijelaskan oleh semua responden pengrajinyang diwawancarai. Selama ini belum pernah mendapat pembinaan secara khsusus dari instansi terkait baik itu tingkat kecamatan atau tingkat kabupaten. Menurut uluk dkk (2001), orang dayak mewariskan ilmu pengetahuan tradisional untuk memanfaatkan dan mengelola hutan dan hutan berfungsi sebagai objek dan tempat belajar untuk mewariskan ilmuilmu tradisional dari orang tua kepada anaknya. Menurut Mitchell (2003) pengetahuan lokal yaitu Setiap masyarakat memiliki kemampuan untuk beradaptasi dengan lingkungan hidupnya karena masyarakat memiliki pengetahuan lokal dalam menguasai alam. Seperti halnya pengetahuan masyarakat mengenai perubahan iklim dan sejumlah gejala-gejala alam lainnya. Dari penelitian yang dilakukan, pengetahuan responden yang berasal dari orangtua tercatat $25 \mathrm{KK}$.

\section{Kesimpulan}

1. Jenis-jenis bambu yang terdapat di Desa Menyabo meliputi bambu Buluh (Schizostacyum zollingeri
Stuedel) dan bambu Abe (Gigantochloa balui K.M Wong).

2. Bentuk Pemanfaatan tumbuhan bambu adalah anyaman, makanan dan pembungkus makanan. bambu buluh (Schizostacyum zollingeri Stuedel) sebagai alat masak dan bahan anyaman. Untuk bambu abe dapat dimanfaatkan sebagai bahan anyaman dan dimanfaatkan juga sebagai sayuran karena rebungnya bisa dimakan.

3. Jenis anyaman yang dihasilkan adalah katoro, nyiruk, atom, keranjang dan jarai.

\section{Saran}

1. Perlu dilakukan pembudidayaan bambu khususnya pada jenis-jenis bambu yang sering dimanfaatkan oleh masyarakat.

2. Kepada pemerintah Khusunya di Kabupaten Sanggau untuk menyediakan pasar atau mengadakan lomba kesenian dari produk tumbuhan bambu, mengingat bahan baku tumbuhan bambu masih cukup berlimpah di hutan khususnya di Desa Menyabo dan tidak adanya pasar khusus penjualan bahan baku tumbuhan bambu.

\section{DAFTAR PUSTAKA}

Andoko (2003), Teknik budidaya bamboo penghasil rebung sebagai sumber pangan. 17-22. Jurnal Teknologi dan Kejuruan. Sumatra Utara

Beer, J D. 2005. Kekayaan Hutan Asia: Makanan, Rempah-rempah, Kerajinan Tangan dan Resin: PT Gramedia Pustaka Utama. Jakarta

Iqbal, M. dkk. 2014. Nilai Ekonomi 
Total Sumberdaya Bambu Di Kecamatan Sajira, Kabupaten Lebak, Banten. Jurnal Mahasiswa Fakultas Kehutanan IPB. Banten

Uluk, Asung, Made S, Wollenberg E, (2001).

Ketergantungan Masyarakat Dayak Terhadap Hutan di Sekitar Taman Nasional Kayan Mentarang, Central for International Forestry Research, Bogor.

Widjaja, E. A. dan Karsono. 2004. Keanekaragaman bambu di Pulau Sumba. Jurnal Biodiversitas, 6 (2): 95-99. Sumba 